then, the entrance between the margins of the upper lip being completely closed, they forcibly break it open with their fore-legs, grasping with them between the margins, and shaking the anthers in order to gain their pollen; thus a good deal of the smooth, powdery pollen grains, falling out of the shaken anthers, is received within the brushes and feathery hairs of their fore-legs, and thence carried to the pollen-collecting orifice of the posterior tibiæ. This incommodious and wearisome labour, although performed by the humble-bees with admirable dexterity and perseverance, contrasts remarkably with the swift and light manner of their gathering pollen, and at the same time sucking honey in flowers adapted to them ; $*$ and many peculiarities of the flowers of $R h$ alpi. nuls would be quite unintelligible under the supposition that pollen-collecting humble-bees were the true and original fertilisers of them. The honey, so copiously secreted in the base of these flowers, would be quite useless to the plant if pollen-collecting humble-bees were its true fertilisers; the minute opening between the two lateral flaps at the tip of the beaked prolongation of the upper lip would likewise be useless, and the closeness of the usual entrance between the margins of the upper lip would be a mere embarrassment to the fertilisers. Supposed, on the contrary, that Lepidoptera are the original fertilisers of $R h$. alpintes, all these peculiarities are easily to be understood as very useful, nay, as indispensable to the plant ; for honey is the only food eagerly searched for by butterflies, and the closeness of the usual entrance, as well as the existence of the minute opening in its very place, are required in order to induce visiting butterflies to insert their proboscis in the only manner which can effect cross-fertilisation. Hence, in spite of the frequent visits of pollen-collecting humble-bees, and in spite of their probably effecting many cross-fertilisations, the flowers of Rh. alpinus are without any doubt to be considered as adapted exclusively to butterflies.

But considering the original function of the under lip as a landing-place for bees, and considering that the most nearly-allied genera, Euphrasia, Métampyrtm, Pedicularis, as well as Rhinanthus cristo-galli, are all adapted to bees, we can hardly doubt that also the ancestors of $\mathrm{K}$. alpinzs have been adapted to cross-fertilisation by bees, and the question may be started, by what connecting forms these ancestors could be transformed into the present form of $R h$. alpinus. We may confidently suppose that they retained the usual entrance for humble-bees, until the beaked prolongation of the upper lip, the minute opening at its tip, and the lateral flaps of this opening were so developed as to secure cross-fertilisam tion by butterflies.

In this respect Rzinanthus alectorolophus is of especial interest; for it represents really what by reflection we are induced to suppose once existed in the connecting forms between $R h$. alpinus and its ancestors (compare Figs. 76-8I). Rh. alectorolophus has indeed retained the usual entrance by which humble-bees may insert their proboscis in order to suck the honey $(c$, Figs. 79, 80), and may be regularly cross-fertilised by sucking humble-bees, whilst at the same time the minute opening (0, Figs. $76-$ 8I) and all those peculiarities which secure cross-fertilisation by sucking butterfiles, are developed.

From the structure of its flowers, as shown by Figs. $78-8 \mathrm{r}$, we should expect that this species would be crossfertilised as well by sucking humble-bees as by butterflies. My direct observation of the fertilisers, however, in the same localities with $R$. alpinus, shows no remarkable difference between $R h$. alectorolophus and $R h$. alpinus. Two species of butterfiles-Colias Plicomone and Pieris Napi-repeatedly inserted their thin proboscis into the minute opening at the tip of the upper lip of $k \hbar$. alectorolophus, apparently sucking honey; numerous specimens

* Compare Esculus Hippocastanum in " $\mathrm{H}$. Müller, Die Befruchtung der Blumen durch Insecten," 1 . $x 55$. of Bombus mastrucatuis, Gerst., $\Varangle+$, terrestris, I. $\not$, Proteus, Gerst, $\measuredangle$, and pratorum, L. $\measuredangle$, were occupied in collecting the pollen of $R h$. alectorolophus in quite the same manner as in $R h$. alpinzs. Only twice I saw humble-bees ( $B$. mastrucatas, Gerst., $\forall)$ sucking the honey of $R h$. alectorolophus, but not legitimately, by the entrance between the margins of the upper lip, but rapaciously; once by inserting their proboscis on the underside between calyx and corolla, and piercing the corollatube a little above its centre; another time by forcibly passing its proboscis through calyx and corolla.

Finally, it is to be noted that self-fertilisation of $R h$. alectorolophus is apparently impossible, for the stigma always projects, just as in Rh, major and alpinus; and when the corolla drops off (in the line $x x$; Fig. 77), and brings its anthers in contact with the stigma, this is already withered. HERMANN MÜlLER

\section{BEATS IN MUSIC *}

$\mathrm{NE}$ of the subjects treated of in Helmholtz's great work on Acoustics is that of "Beats." It is one of much interest, both theoretically and practically: theo* retically, because of the difficulty that attends the investigation of the phenomena, and of the discussions and misunderstandings that have taken place thereon among writers on scientific harmonics; practically, because beats might form an element of great utility in regard to certain practical operations, were it not that their nature and use are at present almost entirely unknown to practical musicians.

The history of the knowledge of beats is curious. They were mentioned as early as 1636 by Mersenne, and were afterwards noticed by Sauveur and others, but no sufficient explanation of their theory was given till the publication in 1749 of the learned work on Harmonics by the celebrated mathematician Dr. Robert Smith, Master of Trinity College, Cambridge. Dr. Youn 2 and Dr. Robison, both eminent writers on acoustics, quarrelled about Smith's work. Young said it added nothing to the knowledge of the subject, whereas Robison declared that it contained the greatest discoveries made since the days of Galileo; the fact, however, being probably that neither of them appreciated the main portions of the work at all. Chladni appears never to have studied the more difficult portion of the subject, and though he gives generally his references very freely, he does not mention Snith's name.

It was only in 1858 that Mr. De Morgan, in an able paper, published in the Cambridge Philosophical Transactions, pointed out the merit of Dr. Smith's investigation, and cleared up its learned obscurity.

Helmholtz treats the subject with his usual ability, but it is very singular that he, like Chladni, makes no allusion whatever to Smith's work, and as it is incredible that he should have passed over such a remarkable and profound theoretical investigation if he had been acquainted with it, I am inclined to believe that the book was unknown to him.

Considering the very few sources of information that exist in regard to beats, and the difficult shape in which this information is embodied, I have thought it might be useful, especially to practical musicians, to attempf to give some account of the subject in a more popular form; and in doing so I will endeavour to introduce the investigations of Smith, in combination with those of the later investigator.

There are three distinct kinds of beats, differing con siderably from each other in the nature of their causes and in the circumstances that attend them, and the confusion between them has caused much error in their

* By W. Pole, P.R.S., Mus, Doc. Oxon. 
investigation. Hence a correct discrimination between them is very desirable.

The first and simplest kind of beat we will distinguish ty the name of the Union Beat, it being produced by the concurrence of two sounds nearly, but not quite, in unison with each other. Let two organ-pipes, or any other sustained sound;, be tuned first exactly in unison ; the combined effect will be equable and smooth, undistinguishable from a single sound. But now let one of the notes be put out of tune, at first very slightly; the result will be a peculiar effect of wavy pulsation or beating. The exact description varies according to the fancy of different hearers, but it is usually said to resemble an alternation of different vowel sounds, like waw, waw, waw, or $y a, y a$, $y a$. The beating, when the notes are but slightly out of tune, will be slow; if the error is made worse, the pulsations will increase in rapidity, till they become too quick to be counted.

This fact is very commonly known, and its experimental exhibition is exceedingly simple and easy. If organ-pipes and the means of tuning them cannot be had, the two sounds may be produced on any wind instrument, which can be easily put into the adjustment necessary. Or one of two unison reeds of a harmonium may be thrown out of tune by weighting it with a little bit of wax ; indeed, in the drawing-room instruments one unison stop is usunlly made purposely out of tune with another, the composicion giving a tremulous effect resembling the shaking of the voice, the stop being named "voix celeste" (in Itain organs a stop called the "vox humana" is formed of tro pipes tuned in a similar way). These are real unison beats with so short a period as to produce the tremulous effect in question. Two unison tuningforks may also be thrown out of tune by attaching wax to the arm of one of them, which will make it a little flatter.

The beats may also be well produced on a violin. Stop A with the fourth finger on the third string, and play it along with the second string open, when the adjustment of the former may be made with the greatest niccty, and if it be put out of tune the resulting beat will som times be so prominent as almost to shake the instrument under the chin. On a pianoforte the beats may also be chserved when one wire of a note is a little sharp or flat of another, although this case is not so favourable for observation, from the sounds not being sustained.

Now, in seeking for the explanation of this phenomenon, a homely preliminary illustration will be useful. Suppose two coffin-makers live next door to each other, and sippose that on some particular day they both strike the hows on their nails at exactly the same rate, and begin exactly together; the effect on a passer-by will be that the sounds of the two will reach his ear simultancously, smoothly, and regularly, and he will have difficulty in distinguishing the combined sound from what would be produced by one workman only. But now suppose that by some change in the fancy of one of the men, $A$, he begins to strike a little faster than his neighbour, making, we will say, eleven strokes to ten of the other, $B$. The effect on the passer-by will be changed, the sounds will reach fis ear irregularly, and, which is the important thing, there will be regular periodical phases appreciable; for it is obvious that at every tenth blow of $B$, or every eleventh of $A$, the blows will coincide, after which they will diverge and become irregular till they coalesce again.

To apply this illustration to the case of the sounds, it must be borne in mind that a sound is transmitted to the ear by waves of the air, each of which consists of an alternate condensation and rarefaction. The coincidences of sound-waves give rise to peculiar effects of interference of various kinds, but it will suffice here to say that when two condensations coincide, the effect will be different to that when the condensation of one wave coin- cides with the rarefaction of another, It will be easily seen that when the vibrations producing two sounds are a little unequal in time, as if, for example, one vibrates eleven times while the other is vibrating ten; there will be periodical coincidences corresponding to those of the blows just mentioned, and it is these periodical coincidences that produce the effect of what is called the beat on the ear.

Having thus established the nature of the beat, we may now go a little further, and see what we can find out about its time, or the length of the period which it involves, and this is a matter which requires careful attention.

We will go back to the illustration of the coffin-makers, and will now assume that the slower workman, B, makes 100 blows in a minute, whereas the quicker workman, $\mathrm{A}$, makes IOI. It will be evident that a coincidence will take place exactly at the end of every minute of time, so that, for these numbers, the periods of coincidence (corresponding to our beats) will be one per minute. Let now A increase his speed to Ioz blows per minute, the other remaining the same; here there will be one coincidence every fiftieth blow of $\mathrm{B}$, or every fifty-first of $\mathrm{A}$, i.e. there will be two coincidences per minute.

It is easy to apply this to the sound-vibrations. Let one note make Ioo double vibrations per second, and let the other note be sharpened to make ioi. Here there will be one coincidence, or, what is the same thing, one beat per second. If the second note is sharpened a little more, so as to make 102 vibrations, there will be two coincidences, or two beats per second.

Hence the rule has been derived, that the number of beats per secoind is equal to the difference of the number of vibrations per second of the two sounds.

This is a simple rule, and it happens to be practicaily an accurate one ; but hasty writers, who have deduced it from one or two simple examples, have omitted to see a curious theoretical difficulty that attends it. Let us go a. step further, and suppose the higher note to make 103 vibrations per second, while the other makes 100: how many beats per second would this give? The rule says three, but if we examine very carefully the succession of sounds, we shali find there will not be three coincidences per second, there would be oniy one, and hence the rule will appear to fail. But if we try the experiment we shall hear that there will be three beats, and hence the theory and the fact do not correspond.

To explain the discrepancy, let us revert again to the illustration of the coffn-makers: supposing $A$ to make 103 , and $B$ 100 strokes per minute, the interval between A's stroke is $=\frac{1}{10}$ of a minute, and between B's $=\frac{1}{105}$. The 33rd stroke of $\mathrm{B}$ will take place after $\frac{3 \mathrm{~S}}{10}$ of a minute, and the 34th of $\mathrm{A}$ after ${ }^{34}$, and as these fractions arc not the same, it is clear that the blows will not coincide, neither will the 66 th and 68 th ; in fact, there will be only one point in each minute when the blows will be heard exactly together.

Yet if the passer-by be asked to count with his watch how many coincidences per minute he hears, he will assuredly say three, and this discrepancy between theory and fact demands to be reconciled.

The explanation was cleverly hit upon by Dr. Young, who ("Experiments and Inquiries respecting Sound and Light," sec. xi.), treating of the subject, mentions "coincidences, or near approaches to coincidences." He saw that. so far as the ear was practically concerned, a near approach would answer the purpose of an exact coincidence equally well; and this clears up all the difficulty. For although the $32 \mathrm{rd}$ and 34 th blows do not come together with theoretical exactness, they come practically so nearly together that the difference between $\frac{33}{100}$ and $\frac{34}{10}$ is only 1 , that is, the difference in time between the two blows is only ${ }_{10} \frac{1}{300}$ of a minute, which no passer-by could appreciate, and he may therefore say they coincide. 
Similarly, with the sounds. Although the IO3 vibration-sound and the roo vibration-sound only coincide with theoretical accuracy once in a second, yet there is, three times per second, a coincidence so nearly accurate (within $\frac{1}{3} \delta \mathrm{g}$ of a second) that the practical effect in producing the beat is the same.

The rule, therefore, is practically right; but it should be qualified scientifically with the following addition:When the two vibration-numbers are prime to each other (i.e. when they are not both divisible by any whole number) the rule is not theoretically accurate, but if the times of vibration are very small (as they always are in practice) the error has no practical effect, and the rule consequently holds good.

With the aid of this rule we can now tell the exact number of unison beats that will correspond to any amount by which the two notes are out of tune; and, vice versâ, we can tell the exact quantity by which two notes intended for unisons are out of tune by simply counting the number of beats they give. For example, suppose the A open string on the violin is played along with the fourth finger note (first position) on the third string, and that the latter is a little sharp, so as to give four beats per second, we know that the upper note will have four vibrations per second more than the other; and as at this point of the scale about twenty vibrations go to a semitone, we can tell that the upper note is about one-fifth of a semitone sharper than the lower one. To effect this, the fourth finger must be moved about one-twelfth of an inch nearer the nut than the former position, and this can be measured if any player think it worth the trouble, as a check to the calculation.

We may next inquire what effect on the ear is produced by changes in the rapidity of the beats. At first, when they are slow, no very unpleasant sensation is perceived, but as they become faster they give a sensation of roughness which is disagreeable in a marked degree, With a further increase of rapidity the effect becomes again less unpleasant, until it arrives at the slight tremulousness already mentioned in the voix celeste and wox humana stops, and which, as it is purposely produced, may be supposed to be rather agreeable than otherwise.

If we carry the error farther, the beats become so fast that the ear ceases to be able to appreciate them, and the beating effect entirely disappears.

Helmholtz, who has paid much attention to this subject, and who has founded on this property of beats some important musical speculations, is of opinion that the disagreeable effect increases gradually until the beats arrive at about thirty per second, where the harshness is at a maximum; that then the unpleasantness lessens as they grow faster, until, at about 100, or something more, per second, the beating effect disappears. Hence he calls from $O$ to this point beating distance for any two notes near each other.

For example, if starting from the treble C, 512 vibrations per second, we sharpen the note to $D t, 546$ vibrations, and then sound this with the original $\mathrm{C}$, we shall get $546-512=34$ beats per second, which gives a very harsh effect. If we go on to D, 576 vibrations, we shall get, for the interval $C$ to $D, 576-512=64$ beats per second, which is less harsh; and if we go on to $C$ with $\mathrm{Eh}$, we shall have $6 \mathrm{I}_{4}-5 \mathrm{12}=102$ beats, which is hardly perceptible. For $\mathrm{C}$ to $\mathrm{E}$, a major third, we have 640 $512=128$ beats, and no one can assert that this interval, when in tune, has anything harsh or disagreeable about it.

A curious question has existed as to what becomes of the beats when they thus vanish. Are they entirely annihilated? or do they in their. more rapid shape produce any other sensible effect of any kind? To explain the answer that was, by early writers, given to this question, one must mention a new phenomenon which occurs in connection with double sounds, namely, what is called the "grave harmonic." When two notes are sounded together they give rise to a third tone, of a fainter strength, and generally lower than both. Examples of this are usually taken from concords : thus, if the following two notes are sounded on an organ, a violin, or any instrument of sustained sounds, and are perfectly in tune, the ear will, with attentive listening, hear a faint third sound resulting therefrom, which will be an octave below the lowest note of the concord, thus If, instead of the fifth, the major third $\frac{2}{8}$ be sounded, in like manner the "grave harmonic" will be an octave lower than before, namely, $\frac{2 \div-0}{2}$. This phenomenon was discovered by Tartini, the eminent violinist, and is often on this account called the "Tartini harmonic."

Now it happens that the number of vibrations of Tartini's harmonic, for any two given notes, is exactly the same as the number of the unison beats for the same notes, as hereinbefore described : and hence the idea arose that when the beats became so rapid as to lose their beating character, they gave rise to the grave harmonic; the explanation naturally presenting itself, that a beat recurring regularly with the proper rapidity would produce on the ear the effect of a musical sound. Dr. Young was the first to publish this explanation: he says ("Experiments and Inquiries respecting Sound and Light," sec. $x i$.), "The greater the difference in the pitch of the two sounds, the more rapid the beats, till at last they cornmunicate the idea of a continued sound, and this is the fundamental harmonic described by Tartini."

Young's theory has been generally accepted wniti within the few last years, and in consequence the kind of beat we have been describing has been called "Tartini's beat." Helmholtz has lately thrown doubt on the correctness of Young's explanation, but the analogy of the numbers may warrant us in retaining the name, as distinguishing this beat from others which we will now proceecl to describe.

( To be continued.)

\section{UNITED STATES NATIONAL ACADENY OF SCIENCES.}

THE half-yearly meeting of the National Acadeny of Sciences was held at Philadelphia, Noy, 2, 3, and 4, 1875 . Prof. Joseph Henry has for several years been conducting the researches of the U.S, Lighthouse Board in respect to Fog Signals and the Transmission of Sound. While these experiments are not yet completed, the results up to the present time give the following indications:-The echo of sound passing over the ocean is more probably due to reflection from the surface of the waves than from the air; sound coming against the wind can certainly be heard at an elevation from a greater distance thax at the sea level; with the velocity of the wiad at about five miles an hour, sound was heard five times further with the wind than against it ; sound is heard furthest with a moderate wind; with a strong wind it is not heard so far as in still air.

Prof. Joseph Le Conte, of California, contributed the results of his observations on mountain ranges of the Pacific coast. The author's theory is that the mountain chains in question were formed wholly by a yielding of the crust of the earth, along given lines, to horizontal pressure ; not, howeyer, resulting in a convex arch filled and sustained by liquid beneath, but by a mashing together of the whole crust, producing close folds and a swelling upwards of the squeezed mass. Prof. Le Conte went on foot through a cut mate by the Central Pacific railroad from near St Francisco Bay eastward, a distance of 30 miles through the Coast 